\title{
Response to the comments of Y.S. Ho to the paper "Influence of contact time, pH, soil humic/fulvic acids, ionic strength and temperature on sorption of U(VI) onto MX-80 bentonite" by Ren XM, Wang SW, Yang ST, and Li JX published in J. Radioanal. Nucl. Chem. 283 (2010) 253
}

\author{
Xuemei Ren $\cdot$ Suowei Wang $\cdot$ Shitong Yang $\cdot$ \\ Jiaxing Li \\ Published online: 6 May 2010 \\ (C) Akadémiai Kiadó, Budapest, Hungary 2010
}

In the published paper entitled "Influence of contact time, $\mathrm{pH}$, soil humic/fulvic acids, ionic strength and temperature on sorption of $\mathrm{U}(\mathrm{VI})$ onto MX-80 bentonite" published in JRNC 283 (2010) 253 [1], the sorption of U(VI) onto MX-80 bentonite was studied by using batch technique to investigate the effect of $\mathrm{pH}$, humic substances, ionic strength and temperature on U(VI) sorption. The sorption mechanism of $\mathrm{U}(\mathrm{VI})$ on MX-80 bentonite was discussed according to the experimental data and some models such as Langmuir, Freundlich, D-R models, and kinetic sorption data was simulated by a pseudo-second-order rate equation. Ho et al. firstly presented the pseudo-second-order rate equation [2,3], and then further developed this frame work in their following research $[4,5]$. In our previous work, we had ever cited the original paper for Langmuir and Freundlich models, and the reviewers gave the comments that the models had been used widely and was not necessary to cite the original paper, such condition is also found in carbon nanotubes (CNTs) that many papers about CNTs did not cite the original paper about CNTs firstly published by Iijima [6]. In the published paper [1], we think that the

X. Ren · J. Li

School of Nuclear Science and Engineering, North China

Electric Power University, Beijing 102206,

People's Republic of China

X. Ren $\cdot$ S. Wang $\cdot$ S. Yang $\cdot$ J. Li $(\bowtie)$

Key Lab of New Thin Film Solar Cells, Institute of Plasma

Physics, Chinese Academy of Sciences, P.O. Box 1126,

230031 Hefei, People's Republic of China

e-mail: lijx@ipp.ac.cn pseudo-second-order rate equation has been widely used and the equation is now famous model to simulate the kinetic sorption. To the fact that the original papers [2,3] were not cited in the published paper [1], it is inaccuracy and this does not mean to show the disrespect to its author, Prof. Ho [2]. In future, it should be careful to cite the references and we wish to cite the papers published by Prof. Ho as Ho's work are interesting and useful to understand the kinetic adsorption process of metal ions on minerals and oxides.

The physicochemical behavior of radionuclides on minerals is quite important to understand the potential pollution of radionuclides in the natural environment. In the published paper [1], the experimental data at macromolecular level is important to understand the adsorption mechanism of radionuclides on minerals. However, the information at micromolecular level such as microstructures and chemical species of radionuclides is more accurate to evaluate the potential behavior in the environment. This information can be achieved from spectroscopy analysis such as TRLFS, EXAFS and XPS.

\section{References}

1. Ren XM, Wang SW, Yang ST, Li JX (2010) J Radioanal Nucl Chem 283:253

2. Ho YS (1995) Ph.D. Thesis, University of Birmingham, Birmingham, UK

3. Ho YS, Wase DAJ, Forster CF (1996) Environ Technol 17:71

4. Ho YS (2006) Water Res 40:119

5. Ho YS, McKay G (2000) Water Res 34:735

6. Iijima S (1991) Nature (London) 35:456 